\title{
Good Things Come to Those Who Wait: The Importance of Professional Development for the Implementation of Differentiated Instruction
}

\author{
Esther Gheyssens $^{1 *}$, Els Consuegra ${ }^{2}$, Nadine Engels ${ }^{2}$ and Katrien Struyven ${ }^{1,3}$ \\ ${ }^{1}$ Department of Educational Sciences, Vrije Universiteit Brussel, Brussels, Belgium, ${ }^{2}$ Department of Teacher Education, Vrije \\ Universiteit Brussel, Brussels, Belgium, ${ }^{3}$ School for Educational Studies, Hasselt University, Hasselt, Belgium
}

OPEN ACCESS

Edited by:

Mats Granlund,

Jönköping University, Sweden

Reviewed by:

Karin Bertills,

Jönköping University, Sweden

Sofia Mavropoulou,

Queensland University of

Technology, Australia

*Correspondence:

Esther Gheyssens

esther.gheyssens@vub.be

Specialty section:

This article was submitted to

Special Educational Needs,

a section of the journal

Frontiers in Education

Received: 13 December 2019

Accepted: 28 May 2020

Published: 30 June 2020

Citation:

Gheyssens E, Consuegra E, Engels N and Struyven K (2020) Good Things Come to Those Who Wait: The Importance of Professional Development for the Implementation of Differentiated Instruction.

Front. Educ. 5:96.

doi: 10.3389/feduc.2020.00096
Differentiated Instruction (DI) is proposed as an approach to create inclusive classrooms. Research shows that professional development is necessary for teachers to implement DI efficiently. This study investigates the effectiveness of a professional development programme (PDP) aimed at strengthening the DI competences of teachers. A quasi-experimental design consisting of a pre-test, post-test and control group was used to study the impact of the programme on teachers' self-reported differentiated philosophies and practices. Questionnaires were collected from the experimental group $(n=284)$ and the control group $(n=80)$. Pre- and post-test results were compared using a repeated measure, ANOVA. Additionally, interviews with a purposive sample of teachers $(n=8)$ were conducted to explore teachers' experiences of the PDP. The results show that the PDP was not effective in changing teachers' $\mathrm{DI}$ competences. Multiple explanations are presented for the lack of improvement such as treatment fidelity, the limitations of instruments and the necessary time investment that change requires. The significance of this study lies in the bridge between the quantitative and qualitative results of the PDP. Moreover, this study exposes the complexity of research on professional development.

Keywords: differentiated instruction, professional development, inclusive education, mixed method, primary education

\section{INTRODUCTION}

Inclusive education is listed at the top of the agendas of policy makers (OECD, 2010; UNESCO, 2016). Consequently, there has been a growing demand to address student diversity in regular classrooms and create inclusive classrooms where students with different abilities, backgrounds and interests can learn alongside each other (Bartolo et al., 2007). To establish inclusive classrooms, teachers need to create effective learning environments that provide sufficient and equal learning opportunities for all students. Differentiated instruction (DI) is rooted in the same pedagogical philosophy as inclusive education, which states that diversity exists in any group of students and that teachers should adjust their instruction accordingly (Lindner et al., 2019). Initially, DI focused mainly on practical applications for gifted students, but later evolved into an approach aimed at creating inclusive classrooms (Lawrence-Brown, 2004). Current theories on DI contend that it is both a teaching philosophy and a practice in which teachers proactively adapt their teaching in response to students' interests, learning profiles and readiness (Tomlinson, 2014). Moreover, when teachers actively respond to differences in learning, students are more motivated and involved in 
their learning processes (Yuen, 2009). Studies on DI have confirmed that, although the concept of DI has been in existence for several years, professional development is needed for teachers to implement differentiated practices successfully (Hootstein, 1998; Brighton et al., 2005). To deal with differences among students, DI requires profound organization and engagement on the part of teachers (Lindner et al., 2019). Therefore, professional development for teachers is recommended to enable them to respond adequately to the changing needs of students throughout their careers (Keay and Lloyd, 2011). This study seeks to explore the effectiveness of a professional development programme (PDP) about inclusive education on teachers' implementation of DI.

\section{THEORETICAL FRAMEWORK Differentiated Instruction (DI)}

In the contemporary classroom, teachers no longer have a choice as to whether to respond to student diversity, they can only decide how to respond (Tomlinson et al., 2003). Numerous frameworks and theories have been developed on how to deal with student diversity, such as adaptive instruction (Corno, 2008), universal design for learning (Edyburn, 2005) and others. This study focuses on Differentiated Instruction (DI) as an approach that deals with student diversity and creates maximum learning opportunities for each student in the same classroom (Tomlinson, 2017; Lindner et al., 2019). DI is highly valued and promoted by educational researchers as a means to meet students' learning needs. It is rooted in the belief that variability exists among any group of students and that it is the responsibility of the teacher to design whole class instruction that can be flexibly adapted to align with students' interests, learning profiles and readiness (Tomlinson, 2017). Classroom applications of DI comprise ongoing assessment and different grouping strategies (individual, duo, homogeneous groups or heterogenous groups). However, effective application of DI teaching practices depends crucially on the philosophy of the teacher (Coubergs et al., 2017; Tomlinson, 2017). For example, a belief that they have an influence on the learning of students has been found to be beneficial for the implementation of DI (Tomlinson et al., 2003; Coubergs et al., 2017).

Despite the promising theories relating to DI, studies have also shown that teachers struggle to implement strategies that require certain insights and professional devotion (Groenez et al., 2018; Lindner et al., 2019). For example, Casey and Gable (2012) conducted a survey to identify how efficacious novice teachers feel in applying differentiated instruction to a diverse body of students. They compared the level of confidence teachers with varying years of experience had in adopting DI strategies. The strategies that novice teachers felt most confident about included varying the learning pace, assessing students' interests and using flexible grouping. Strategies they were least confident about were active learning, grading students' learning as a reflection of individual growth and assigning appropriate exercises based on students' learning preferences. Additionally, there were no significant differences between the numbers of certificates concerning perceptions of preparedness and DI. However, the outcomes showed that teachers with more certificates and thus more training felt more confident about using DI. Furthermore, teachers who reported being prepared for DI were more confident about using DI strategies and vice versa (Casey and Gable, 2012). Also focusing on professional development for differentiation, Brighton et al. (2005) examined the impact on teachers and students of a staff development programme related to DI in a heterogeneous classroom. This intervention was aimed at broadening teachers' knowledge of DI to satisfy the learning needs of their students. The staff development programme lasted 3 years and was delivered to 76 teachers in six middle schools. The outcomes of the study showed that building knowledge on DI requires a great deal of time and effort on the part of teachers. Practical obstacles included large class sizes, a lack of planning time and limited materials. The biggest challenge for most teachers was that DI forces them to change their prior beliefs about teaching and learning (Brighton et al., 2005).

Whilst these studies address the preparedness, confidence and knowledge needed to implement DI, de Neve et al. (2015) investigated the interplay between teacher autonomy, the characteristics of professional learning and teacher self-efficacy as hypothesized determinants of professionalization in DI. Based on their results, they suggested that, for professional development to succeed, novice teachers should be encouraged to discuss their thoughts with colleagues, share DI knowledge and experiences and be aware of their shared responsibility in satisfying the various needs of students. In addition to collaboration, teacher autonomy as a job resource is also important for teachers' professional development. Novice teachers should be given opportunities to apply DI, test DI strategies and develop DI techniques for themselves. Latz et al. (2008) examined the impact of peer coaching on teachers' understanding and ability to implement DI for gifted students. They found that, regarding the use of differentiation, two thirds of the mentors initially reported that differentiation was implemented to a very limited extent. The reasons were that teachers were not familiar with differentiation, that they understood the meaning of differentiation but did not know how to implement it, or that they lacked the confidence to do so. However, teachers claim that the mentoring programme had a positive impact on the practice of differentiation. From these findings, Latz et al. (2008) concluded that, for a successful mentoring programme, time must be provided for the communication process between the mentor and the teachers, observations, and meetings. Moreover, its value should be prioritized by both teachers and school administrators so that teachers have sufficient time to explore the implementation of DI in their daily teaching.

In short, several studies have highlighted the importance of professional development in the implementation of DI. Incentives for implementing DI are confidence in the teachers (Casey and Gable, 2012), collaboration with colleagues (de Neve et al., 2015) and peer coaching (Latz et al., 2008). Furthermore, it is important to understand that implementing DI requires time and effort (Brighton et al., 2005). With these specific aspects in mind, the characteristics of successful professionalization in general are now discussed. 


\section{Professional Development}

Professional development is essential if teachers are to respond adequately to the changing needs of students during their careers (Keay and Lloyd, 2011; EADSNE (European Agency for Development in Special Needs Education), 2012). In a narrative review, Merchie et al. (2016) identify nine characteristics of effective professional development: (1) the starting point is the needs and questions of teachers as they are the owners of what and how they learn; (2) the content is based on scientific research findings and linked to the teacher's questions; (3) the content is related to the teacher's goals, the school policy and the broader educational policy; (4) sufficient attention is paid to the concrete translation of knowledge into daily educational practice; (5) active learning occurs through inquiry-based learning and reflection on professional and academic knowledge; (6) it takes place in educational settings; (7) it occurs through collaboration with internal and external colleagues; (8) it is an extensive and intensive programme, spread over a substantial period of time with continual, permanent support throughout and (9) the supervisor is of high quality and is competent in giving and receiving constructive feedback and imparting other coaching skills (Merchie et al., 2016).

To stimulate the implementation of DI we focus on two of these characteristics. First, active learning occurs through inquiry-based learning. Brighton et al. (2005) stated that the biggest challenge for most teachers was that DI questions their prior beliefs. To participate in professional development, teachers' mindsets need to be open to responding to new forms of diversity and new opportunities for collaborating with colleagues. This can be accomplished through inquiry-based learning. This requires a research-oriented attitude from teachers that encourages critical reflection on their classroom practice in collaboration with partners (Harinck and van Brakel, 2009). A research-oriented attitude toward what is needed in their own classrooms, for their students and with their cooperation partners, encourages teachers to retain ownership of their professional development and actively to shape it themselves in line with their learning objectives (Bradbury, 2015).

Second, collaboration with internal and external peers is essential for effective professionalization (Merchie et al., 2016) and beneficial for DI implementation (Latz et al., 2008; de Neve et al., 2015). By discussing and coordinating their individual learning activities, teachers work not only on their individual competences and the development of talent, they also stimulate the collective development of knowledge in the school. In this way, the school becomes a learning organization. Generated by teachers, this organization has the learning capacity to develop the required knowledge in a changing context and to develop and use the competences of teachers in order to continue work on its mission and objectives (Baert et al., 2011). Moreover, a strategic professionalization policy in schools determines how the transfer of knowledge to the workplace is facilitated (Baert et al., 2011).

\section{RESEARCH GOAL AND QUESTIONS}

As discussed, existing research has yielded promising findings that have associated professional development with teachers' implementation of differentiated practices (Brighton et al., 2005; Latz et al., 2008). The present study designs a professional development programme (PDP) based on two goals: (A) to create an open mindset for teachers to appreciate and exploit student diversity in the classroom and (B) to stimulate collaboration between teachers to foster inclusive teaching competence. It then explores the impact of this PDP on achieving these two goals. To facilitate this, the following research questions were formulated: (1) How did teachers' self-reported philosophy and DI practices change after participation in the PDP? and (2) why was the PDP (not) successful according to the participating teachers? To answer these questions, the results from an experimental group and control group were compared.

\section{RESEARCH CONTEXT}

Like many other regions and educational systems, Flanders has for several years been faced with the demand for more inclusive classrooms. Schools and teachers are now searching for ways to create an inclusive education system where students with special educational needs are integrated into the classroom. This study focuses on primary education, which is organized for children from 6-12 years and consists of 6 subsequent years. A child usually starts primary education at the age of six after finishing kindergarten (three to 6 years of age) and finishes primary school at the age of twelve. Unlike kindergarten, primary education is compulsory for Flemish children. There is usually one teacher who is responsible for teaching all subjects, with the exception of physical education which is generally taught by a subjectspecific teacher.

\section{METHODOLOGY}

\section{Research Design}

A quasi-experimental design with a pre-test at the beginning of the academic year and a post-test at the end of the academic year was devised. There were two conditions. Condition 0 or the control group included 14 schools who participated in a control condition and completed a pre-test and post-test. Condition 1 or the experimental group included 18 schools who participated in the experimental PDP during the academic year 2017-2018, the aim of which was to strengthen teachers' competences in order to create inclusive classrooms (Figure 1). In the experimental schools, three to five teachers (depending on the school size) participated in the intervention sessions. Each school could decide for themselves how they composed this so-called core team. In some schools this was on a voluntary basis while in other schools the school leader chose the teachers or there was a process of mutual agreement. The intervention took place during regular school hours, during which time the participating teachers were temporarily replaced by colleagues or other solutions were found so that students did not miss out on any teaching.

\section{Professional Development Programme}

Drawing on research on effective professionalization (Merchie et al., 2016), a professionalization trajectory was developed and implemented to strengthen the competences of teachers 


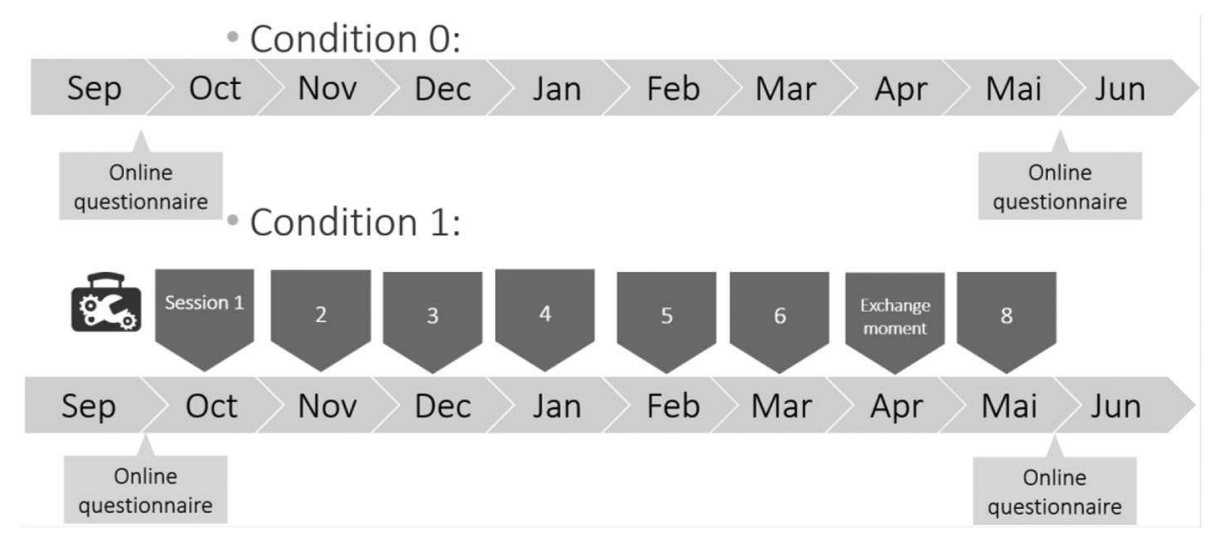

FIGURE 1 | Quasi-experimental design.

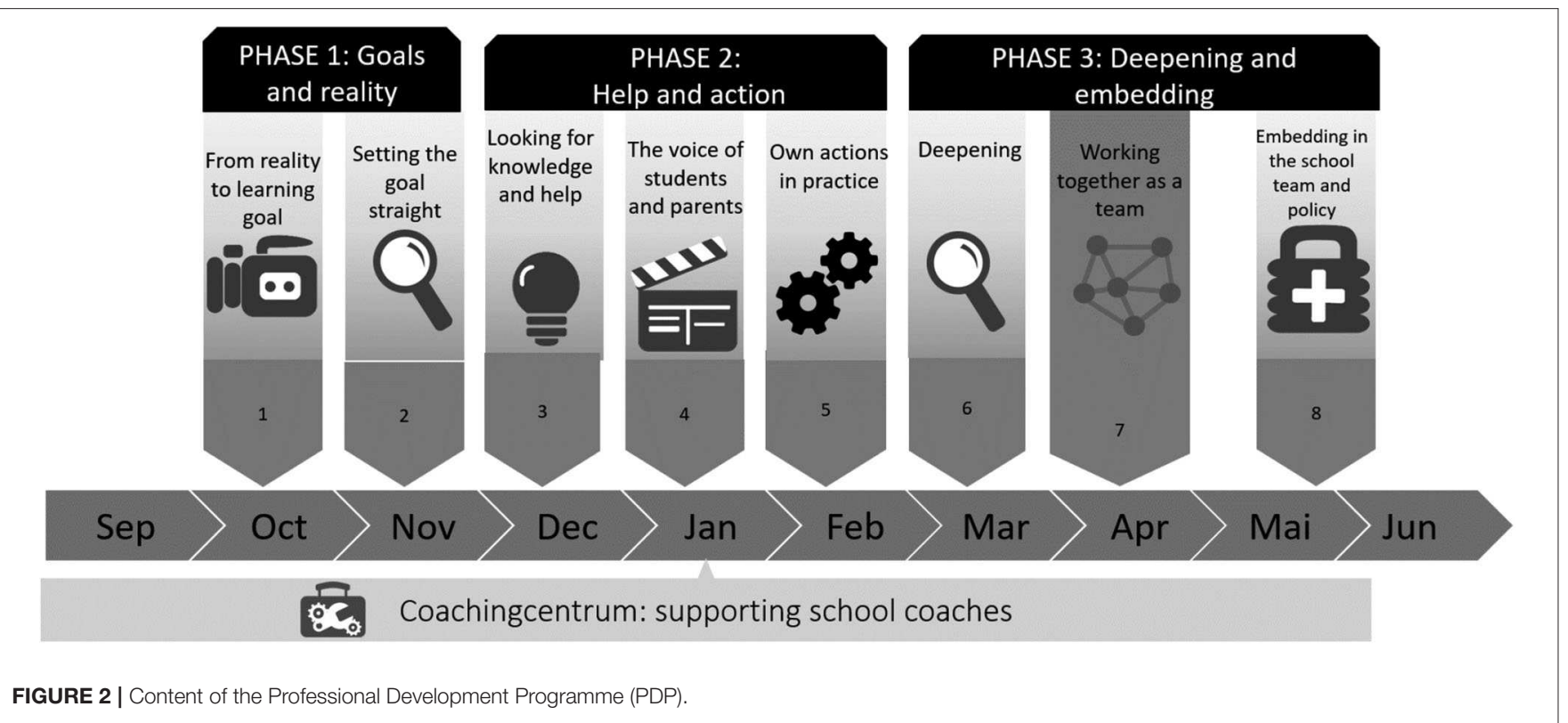

in creating inclusive learning environments. The two objectives of the project: (A) appreciating and exploiting diversity and (B) establishing collaboration between teachers, were central to the intervention. The PDP was facilitated by external educators drawn from outside the school (pedagogic counselors) or internal educators drawn from the school team (selected teachers). They were purposely trained for their role as facilitators (or coaches) by attending several courses throughout the academic year. During these sessions, the GRROW model of inspiring coaching was applied (Clement, 2015). This comprised the following steps to support the personal learning and growth processes of the teachers. Goal: what is the goal, what do teachers want to achieve? Reality: what does reality look like at this moment? Resources: which resources can be applied? Who or what could help teachers? Opportunities: what options and possibilities are there? Will: which action plan will the teachers undertake? Which steps are they going to take now? Coaches were encouraged to tailor the PDP to the schools' needs.

The PDP is predicated on the premise that, to respond adequately to the changing needs of students during their career, teachers need to continue to work on their own professional development in a focused and active manner [EADSNE (European Agency for Development in Special Needs Education), 2012]. The coach should guide the teachers during this process from defining their goal to undertaking an action plan. A research-oriented attitude toward what is needed in the classroom, in collaboration with colleagues, encourages teachers to shape their professional development toward the goals they have in mind. Therefore, the PDP is based on a cycle of action research that is aimed at providing answers to these learning and practical questions (Bradbury, 2015).

The professionalization process consisted of three phases (Figure 2). The first phase involved obtaining a clear picture 
of what exactly teachers wanted to achieve in order to make the classroom more inclusive. Teachers could indicate how they wanted to grow and set goals for themselves as individual teachers. Commonly chosen goals were implementing differentiated strategies, ongoing assessment and dealing with demotivated students. The second phase involved taking actions to realize these goals to make the classroom more inclusive and to think about who or what can support the teacher in achieving this. In this phase, teachers needed to acquire knowledge and seek help to realize their goals. Exchanging information and showing video tapes of their lessons to other members of the team was encouraged. The teachers also got to watch a new created documentary that demonstrates the voices of students with a (learning) disability and their parents and how they experience inclusive education. The third phase involved sharing the knowledge and experiences gained during their learning processes with the school team and embedding these into the school policy. The purpose was to enable teachers from the core team (about five teachers) to give updates to their colleagues during meetings. There was also an exchange moment during the annual professional development day organized by each school (Figure 2).

The basic route proposed to schools was a model route comprising eight sessions of $3 \mathrm{~h}$. Although this was intensive, research has shown that programmes which are sufficiently long and intensive have a better chance of resulting in effective professionalization (Merchie et al., 2016). Schools planned these meetings at times that suited them over the course of the entire academic year. While other studies (e.g., Brighton et al., 2005) suggest that PDP should last longer than 1 year, this PDP lasted 1 year due to funding and other practical reasons.

\section{Sample}

Schools were selected during 2016-2017 through stratified sampling. First, schools were sampled based on an equal representation of each geographical region within Flanders (Belgium) and a proportional representation of rural vs. city schools. For each school that declined to participate in the study, a matched school from the next random sample was contacted. In total, 99 primary schools were contacted, of which 32 (response rate $31 \%$ ) agreed to participate. Once a school had agreed to participate in the project, all the teachers were invited by e-mail to complete several instruments. Each teacher received an invitation with a personal login so that he/she could access an online platform and complete the instruments in their own time. Teachers were given several weeks to complete the instruments during October-November 2017. The response rate among schools for the pre-test was 614 teachers or $76.37 \%$. At the end of the academic year, teachers were again invited to complete the same questionnaire through the same platform. As before, they were given several weeks in June 2018 in which to complete the survey. The response rate among schools at this stage was 364 teachers or $45.27 \%$. The mean age of the teachers was 41.38 years $(S D=10.53)$, the average number of years of experience was 16.8 years $(S D=10.46)$ and there was an over-representation of female teachers as $90.6 \%$ of the teachers were female $(N=556)$.
TABLE 1 | Participating schools in the qualitative sample.

\begin{tabular}{lccc}
\hline & SCHOOL A & SCHOOL B & SCHOOL C \\
\hline $\begin{array}{l}\text { Urban or rural school } \\
\begin{array}{l}\text { Total number of } \\
\text { teachers in the school }\end{array}\end{array}$ & Urban & Urban & Urban \\
$\begin{array}{l}\text { Total number of } \\
\text { students in the school } \\
\% \text { of students with a } \\
\text { non-Belgian nationality } \\
\% \text { of students with a } \\
\text { different mother tongue } \\
\% \text { of students with low } \\
\text { SES }\end{array}$ & $12.9 \%(N=52)$ & 64 & 45 \\
\hline
\end{tabular}

TABLE 2 | Participating teachers.

\begin{tabular}{lllcc}
\hline Pseudonym & School & Gender & Age $^{*}$ & Experience $^{*}$ \\
\hline Andres & A & M & $20-30$ & $1-5$ years \\
Anna & A & F & $30-40$ & $5-10$ years \\
Alice & A & F & $30-40$ & $5-10$ years \\
Boris & B & M & $30-40$ & $5-10$ years \\
Bob & B & M & $30-40$ & $5-10$ years \\
Barbara & B & F & $30-40$ & $5-10$ years \\
Cristina & C & F & $30-40$ & $15-20$ years \\
Chelsey & C & F & $30-40$ & $15-20$ years \\
\hline
\end{tabular}

*To protect the privacy of the respondents, age and years of experience are presented in categories.

This is not surprising since there is an overall overrepresentation of female teachers in primary education.

After agreement to participate in the stratified sample, there was, the following academic year, an additional call to the 32 participating schools to cooperate in qualitative research, more specifically, in interviews. Three primary schools from the large sample responded to this call to participate in qualitative data collection, all of which were urban schools with a diverse student population. Table 1 presents the following background information on these three schools participating in the qualitative research: the number of students and teachers, the diversity within these schools in terms of students with a non-Belgian nationality or a mother tongue other than the instruction language (Dutch) and the percentage of students with low socio-economic status. The latter is displayed because schools receive additional resources based on this percentage. The criteria for low socio-economic status are determined by the Flemish Government.

Within these three schools, eight teachers who participated in the PDP were selected based on their willingness to take part in the interviews (Table 2). No stratified sampling was applied here, the question to participate in interviews was asked of all schools from the large representative sample and all the teachers who replied to this call are included in this small sample which is not representative of the Flemish teacher population. Teachers were given pseudonyms to protect their privacy and that of their 
school. To distinguish which school they were from, teachers from school A were given names that started with an 'A' and so on.

\section{Data Collection DI-Quest Instrument: Perceptions of Differentiated Instruction}

In a previous validation study (Coubergs et al., 2017), an exploratory and confirmatory factor analysis on a questionnaire about DI led to the development of the DI-Quest instrument. This self-report instrument measures the practice of DI in terms of five different factors. Two of these factors focus on the philosophy of the teachers: the growth mindset and the ethical compass. The first factor growth mindset is based on Tomlinson (2011) that states that a teacher's mindset can affect the successful implementation of DI (Sousa and Tomlinson, 2011). Teachers with a growth mindset believe that, if students are provided with commitment and engagement, they can learn more than was initially thought (Dweck, 2006). The second philosophical factor is the ethical compass. This envisions the use of curriculum, textbooks and other external influences as a compass for teaching rather than observations of the student (Tomlinson and Imbeau, 2010; Coubergs et al., 2017). An ethical compass that focuses on the student embodies the development of meaningful learning outcomes, devises assessments in line with these and creates engaging lesson plans designed to enhance students' proficiency in achieving their learning goals (Tomlinson and Imbeau, 2010). An overly rigid adherence to a curriculum that does not take students' needs into account negatively predicts the use of adaptive teaching based on differences in learning (Coubergs et al., 2017). Two other factors contain practical principles: flexible grouping strategies and the continual process of using students' output as input for learning and teaching. Flexible grouping refers to switching between homogeneous and heterogeneous groups that help students to progress based on their abilities (when in homogeneous groups) and facilitates learning through interaction (when in heterogeneous groups) (Whitburn, 2001). Given that the aim of DI is to provide maximum learning opportunities for all students, variation between homogeneous and heterogeneous teaching methods is essential. The other differentiated practice factor in the DIQuest instrument is output $=$ input. This factor represents the importance of using output from students (such as information from conversations, tasks, evaluations and classroom behavior) as a source of information, not only for the learning process by providing them with feedback, but also for the teacher in terms of teaching (Hattie, 2009). Assessment and feedback are not the final steps in the process of teaching, but they are an essential part of the process of teaching and learning (Gijbels et al., 2005). In this regard, Coubergs et al. (2017) state that including feedback as an essential aspect of learning positively predicts the self-reported use of adaptive teaching. The final factor relates to adapting teaching to the three kinds of differences in learning: students' readiness, learning profiles and interests (Tomlinson et al., 2003; Coubergs et al., 2017). Table 3 presents example items from this survey and the alpha score of each variable. Responses to the eight items on the Flexible Grouping scale were given on a 7-point Likert scale ranging from "I totally disagree" to "I totally agree." Responses to the remaining 12 from the scales output=input and Adaptive Teaching were given on a 7-point Likert scale ranging from "never" to "always" to provide a frequency measure. This instrument was validated in a previous study with 1,573 teachers in Flanders (Coubergs et al., 2017).

\section{Interviews}

In addition to the questionnaire, interviews were conducted with a small sample of teachers. At the end of the academic year, eight

TABLE 3 | The DI-Quest instrument.

\begin{tabular}{|c|c|c|}
\hline Scale & Items & Cronbach alpha \\
\hline Flexible grouping & $\begin{array}{l}\text { I regularly change between working with homogeneous and heterogeneous groups. } \\
\text { I teach my students to help each other. } \\
\text { I explicitly make sure I have a good relationship with all my students. } \\
\text { During my lessons, students need to work together in order to progress in their learning processes. } \\
\text { I make sure that every student has a specific function in my classroom. } \\
\text { Working in heterogeneous groups gives my students the opportunity to learn from each other. } \\
\text { I make sure that every student who needs extra guidance will get this. } \\
\text { I differentiate by switching between working with heterogeneous and homogeneous groups. }\end{array}$ & 0.813 \\
\hline Output $=$ input & $\begin{array}{l}\text { I use assessment to gain insight into the learning processes of my students. } \\
\text { I use assessment to assess in what way I can adjust my lessons to the learning processes of my students. } \\
\text { I teach my students how to cope with feedback. } \\
\text { My students get the opportunity to rework a task based on given feedback. }\end{array}$ & 0.751 \\
\hline $\begin{array}{l}\text { Adaptive teaching to students' interest, } \\
\text { readiness and learning profile }\end{array}$ & $\begin{array}{l}\text { I choose the learning content and teaching methods based on my students. } \\
\text { I adjust my assessment based on my students (or groups of students). } \\
\text { During my lessons, different students work on different tasks with a different level of difficulty. } \\
\text { Every student will receive the same assessment. } \\
\text { During my lessons, my students can decide with me on which assignment they need to work. } \\
\text { Knowing my students, I select the learning content, materials and teaching methods. } \\
\text { Based on their learning profile, I let my students choose between learning content and teaching method. } \\
\text { During my lessons, I choose the learning content and teaching methods for my students based on the } \\
\text { learning profile of my students. }\end{array}$ & 0.869 \\
\hline
\end{tabular}


teachers who participated in the PDP (Table 2) were asked during an open interview about the progression of the programme. In particular, they were asked what they found positive about the PDP, what they had learned, what influence the programme had on their implementation of differentiating practices, what influence the PDP had on their collaboration and what they felt could be improved in the intervention.

\section{Analysis}

In the quantitative phase, to gain insight into changes in teachers' self-reported DI philosophy and DI practices, the statistical analysis began by screening the descriptive results of the DIQuest. A repeated measures ANOVA was then conducted to compare the mean outcomes (five scales of DI-Quest) at two time points (pre-test vs. post-test) and between two groups (control condition vs. experimental condition). All statistical analyses were conducted using IBM SPSS Statistics 25.

In the qualitative phase, after transcribing and anonymising the interviews, content analysis was applied to analyse teachers' experiences in the PDP. This method was chosen because it links the findings to their context, e.g., the school in this study (Bengtsson, 2016). The first step in the analysis was to identify and categorize experiences for the three phases of the intervention: goals and reality, help and actions, deepening and embedding. In addition, examples from teachers within these categories led to smaller categories based on the inductive codes. NVivo software was used to support the process of open inductive coding and content analysis. The results are represented based on the frequency that teachers report positive or negative aspects of the PDP.

\section{RESULTS}

\section{Effectiveness of the PDP}

\section{Changes in Teachers' Philosophies of DI}

A repeated measures ANOVA with a sphericity assumption showed that teachers' growth mindset $\left[F_{(1,362)}=11.505, p=\right.$ $0.001, \eta_{\mathrm{p}}{ }^{2}=0.031$ ] differed significantly between time points; however, no significant difference was found between the control and experimental group $\left[F_{(1,362)}=3.002, p=0.084, \eta_{\mathrm{p}}{ }^{2}=\right.$ $0.008]$. The ethical compass did not differ between time points $\left[F_{(1,287)}=0.048, p=0.826, \eta_{\mathrm{p}}{ }^{2}=0.000\right]$ or between the control and experimental group $\left[F_{(1,287)}=1.289, p=0.257, \eta_{\mathrm{p}}{ }^{2}=0.004\right]$. To sum up, a small negative effect was found for the time in growth mindset, but no changes were detected within the ethical compass (Table 4). In addition, no differences were found between teachers' background variables, such as age and years of teaching experience.

Post hoc tests using a Bonferroni correction indicated a change in teachers' growth mindset toward students over time in both the experimental group and the control group. The results indicated a decrease in teachers' growth mindset, indicating that they were more fixed in their mindset at the end of the academic year than at the beginning (Figure 3). However, these differences were not significant $(p=0.084)$.

\section{Changes in Differentiated Practices}

With regard to teachers' differentiated practices, a repeated measures ANOVA with a sphericity assumption showed that flexible grouping $\left[F_{(1,287)}=3.827, p=0.051, \eta_{\mathrm{p}}{ }^{2}=0.013\right]$ and output $=$ input $\left[F_{(1,287)}=1.880, p=0.028, \eta_{\mathrm{p}}{ }^{2}=0.017\right]$ changed significantly over time, whereas adaptive teaching did not $\left[F_{(1,287)}=2.082, p=0.150, \eta_{p}{ }^{2}=0.007\right]$. Furthermore, only output $=$ input differed significantly $\left[F_{(1,287)}=3.878, p\right.$ $\left.=0.050, \eta_{\mathrm{p}}{ }^{2}=0.013\right]$ between the control and experimental group (Table 5). In addition, no differences were found between teachers' background variables, such as age and years of teaching experience.

Post hoc tests using a Bonferroni correction revealed a significant change over time between the control and experimental group for output $=$ input. The results indicate a status quo for teachers from the experimental schools and a decrease for teachers from the control schools (Figure 4).

\section{Qualitative Results}

Before considering the second research question, descriptive results were presented to the teachers who participated in the intervention and agreed to the interview. Table 6 displays their mean scores on each of the variables during the first and second measurement period.

Although no statistical effectiveness scores can be determined from these results, several are striking. For example, for the adaptive teaching variable, six teachers had a higher score after participating in the intervention. Only one teacher scored lower on this variable while another did not complete the survey the second time. For the practice variables of flexible grouping and output $=$ input, three and four teachers increased their adoption of these differentiated practices while the others remained more or less the same. Regarding the philosophical variables, in the growth mindset only three teachers exhibited an increase while in the ethical compass only two teachers did. The overall trend, however, was for teachers' mindset toward DI to decrease during the second wave.

TABLE 4 | Repeated measures ANOVA for differentiated philosophies.

\begin{tabular}{|c|c|c|c|c|c|c|}
\hline \multirow[t]{2}{*}{ Variable } & \multicolumn{3}{|c|}{ Time } & \multicolumn{3}{|c|}{ Time*Condition } \\
\hline & $F$ & $p$ & $\eta_{p}^{2}$ & $\boldsymbol{F}$ & $p$ & $\eta_{p}^{2}$ \\
\hline Growth mindset & $F_{(1,362)}=11.505$ & $0.001^{*}$ & 0.031 & $F_{(1,362)}=3.002$ & 0.084 & 0.008 \\
\hline Ethical compass & $F_{(1,287)}=0.048$ & 0.826 & 0.000 & $F_{(1,287)}=1.289$ & 0.257 & 0.004 \\
\hline
\end{tabular}

*Indicates that this number is statistically significant. 

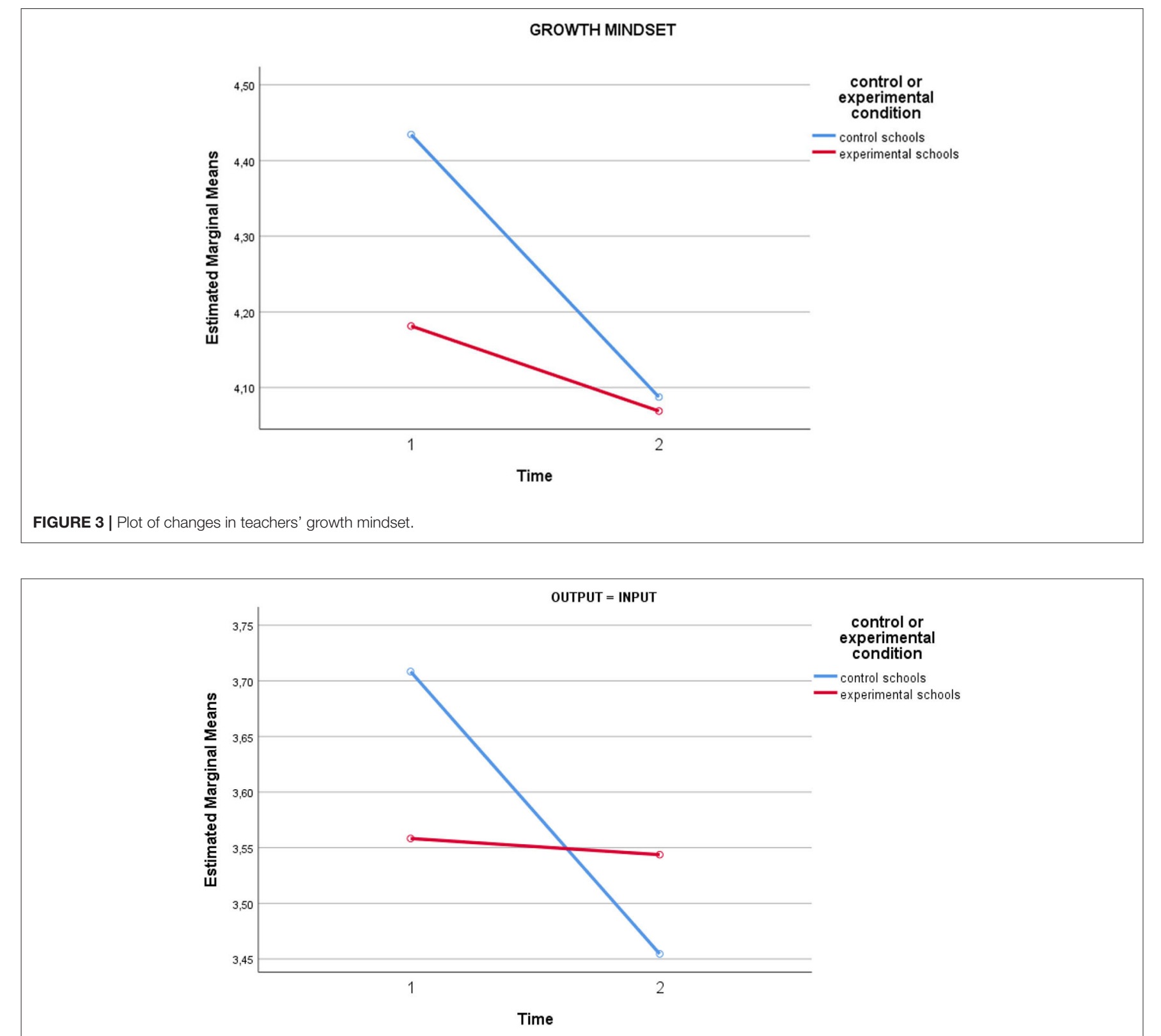

FIGURE 4 | Plot of changes in teachers' use of output = input.

TABLE 5 | Repeated measures ANOVA for differentiated practices.

\begin{tabular}{|c|c|c|c|c|c|c|}
\hline Variable & \multicolumn{3}{|c|}{ Time } & \multicolumn{3}{|c|}{ Time*Condition } \\
\hline Output = Input & $F_{(1,287)}=1.880$ & 0.028 & 0.017 & $F_{(1,287)}=3.878$ & $0.050^{*}$ & 0.013 \\
\hline Adaptive Teaching & $F_{(1,287)}=2.082$ & 0.150 & 0.007 & $F_{(1,287)}=0.051$ & 0.821 & 0.000 \\
\hline
\end{tabular}

*/ndicates that this number is statistically significant.

\section{Teachers' Satisfaction With the PDP}

During the interviews teachers were asked to describe whether they were satisfied with the trajectory and outcomes of the PDP.
Figure 5 illustrates the number of teachers that mention a specific advantage of the PDP. The two most mentioned advantages of the intervention programme were noted by six out of the eight 
TABLE 6 | Descriptive results for the variables over time.

\begin{tabular}{|c|c|c|c|c|c|c|c|c|c|c|}
\hline \multirow[b]{2}{*}{ Teacher } & \multicolumn{5}{|c|}{ Variables wave 1} & \multicolumn{5}{|c|}{ Variables wave 2} \\
\hline & $\begin{array}{l}\text { Growth } \\
\text { mindset }\end{array}$ & $\begin{array}{l}\text { Ethical } \\
\text { compass }\end{array}$ & $\begin{array}{l}\text { Fexible } \\
\text { crouping }\end{array}$ & $\begin{array}{c}\text { Output }= \\
\text { input }\end{array}$ & $\begin{array}{l}\text { Adaptive } \\
\text { teaching }\end{array}$ & $\begin{array}{l}\text { Growth } \\
\text { mindset }\end{array}$ & $\begin{array}{l}\text { Ethical } \\
\text { compass }\end{array}$ & $\begin{array}{l}\text { Fexible } \\
\text { grouping }\end{array}$ & $\begin{array}{c}\text { Output }= \\
\text { input }\end{array}$ & $\begin{array}{l}\text { Adaptive } \\
\text { teaching }\end{array}$ \\
\hline Andres & 4.75 & 2.50 & 4.50 & 3.75 & 2.88 & \multicolumn{5}{|c|}{ Data missing } \\
\hline Anna & 4.50 & 2.17 & 4.63 & 3.25 & 2.88 & 4.00 & $3.17^{\star}$ & 4.63 & 2,50 & 2,75 \\
\hline Alice & 4.25 & 2.50 & 5.00 & 4.75 & 4.13 & 3.80 & 2.17 & $5.25^{\star}$ & $5,00^{*}$ & $5,00^{*}$ \\
\hline Boris & 4.00 & 2.83 & 3.38 & 4.75 & 2.19 & 3.80 & 2.00 & $4.25^{\star}$ & 4,00 & $2,50^{\star}$ \\
\hline Bob & 4.50 & 3.00 & 4.75 & 2.50 & 1.88 & $5.00^{\star}$ & 1.17 & 4.50 & $4,25^{\star}$ & $2,13^{\star}$ \\
\hline Barbara & 3.25 & 4.33 & 5.25 & 4.00 & 3.13 & $3.60^{\star}$ & 2.00 & 5.25 & 3,50 & $3,50^{\star}$ \\
\hline Cristina & 5.00 & 3.33 & 4.50 & 3.50 & 1.63 & $5.40^{\star}$ & 1.00 & $4.75^{\star}$ & $5,00^{*}$ & $1,88^{\star}$ \\
\hline Chelsey & 3.25 & 4.33 & 4.38 & 3.50 & 2.50 & 1.00 & $5.00^{*}$ & 4.63 & $3,75^{\star}$ & $3,50^{\star}$ \\
\hline Mean & 4.19 & 3.14 & 4.99 & 3.50 & 3.27 & 4.06 & 3.08 & 4.97 & $3.54^{*}$ & $3.33^{\star}$ \\
\hline
\end{tabular}

*Values that are higher during the second measurement than the first.

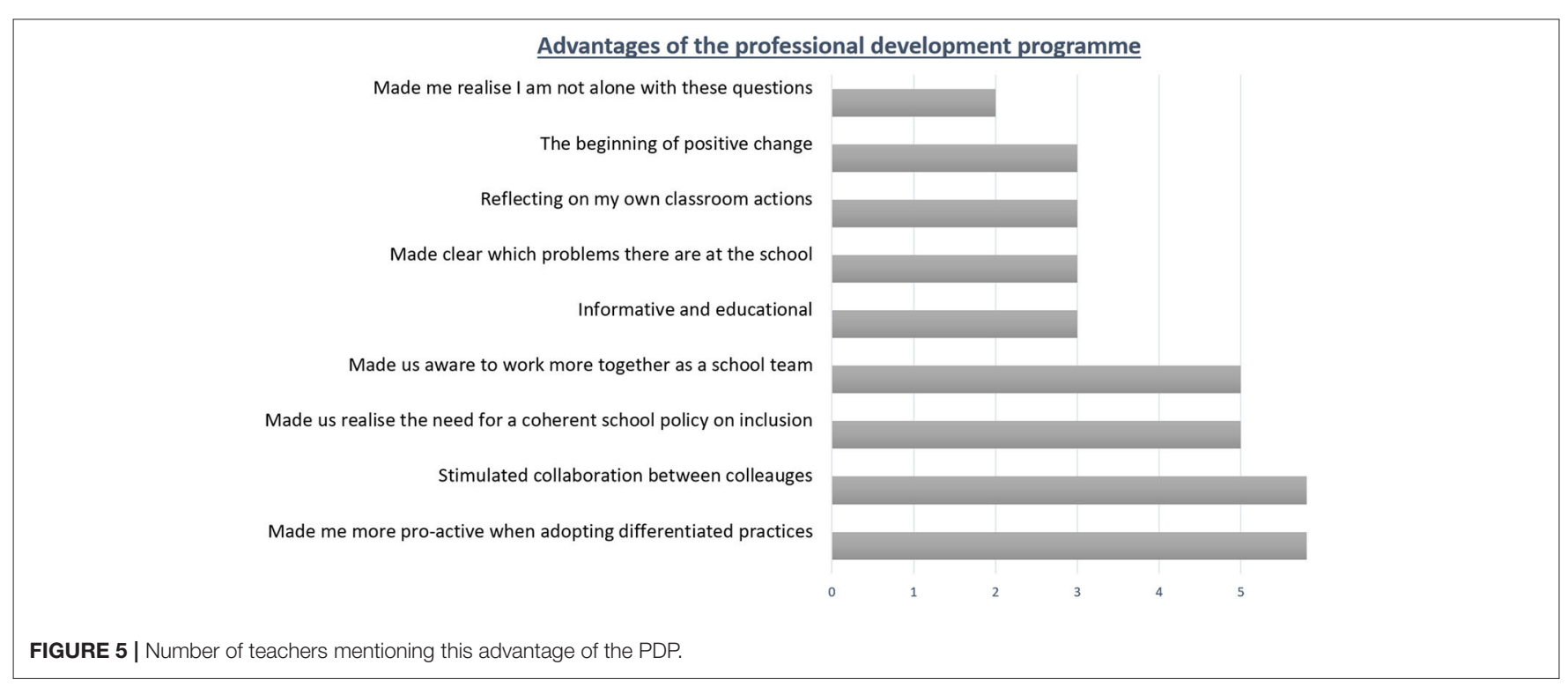

teachers. The first advantage was not that teachers necessarily implemented more differentiated practices but that they did so more consciously and thought it through. The other commonly mentioned advantage was that they liked the fact there was a time and a place to discuss these topics with colleagues and exchange information about their classroom practices. The second most mentioned advantage (five out of the eight teachers) was that they were more oriented toward the school. The PDP made teachers realize they needed to work together more often, be more consistent, and develop a more coherent school policy on how to deal with inclusive practices. For example, Anna stated: "In each grade certain differentiated practices are approached differently. It is confusing for students that they have to learn new rules of what is possible; for example, in using help tools attached to a practice every year. It would benefit us all if we were more consistent throughout the years." The third most commonly mentioned advantage was that the PDP was informative, it made clear where the problems were situated in the school and it helped teachers to reflect on their classroom actions. For some teachers, the intervention even symbolized the beginning of change, which is the most important intention of the PDP.

Teachers were also asked to state what dissatisfied them about the PDP and what they felt could have been better. The main issue that five out of the eight participating teachers had with the PDP was that, overall, they were disappointed with the results (Figure 6). They found no solutions for the problems they were facing when creating inclusive classrooms. For instance, Boris stated: "I still don't have an answer on how to reach all students, how to deal with all those differences in the classroom." They had higher expectations and were dissatisfied with the progress they made during the intervention. Moreover, the PDP made the implementation of DI strategies appear unrealistically easy. Teachers had the feeling that what was discussed during the session differed from the reality they were facing. As Andres observed: "The things discussed during the sessions were always so positive, for example differentiated instruction, the PDP made 
Disadvantages of the professional development programme

Too short in time

Too much talking about problems and not enough action

The coach did not guide the teachers enough

Vague and not to-the-point

Made things look too positive, it was not realistic enough

Dissapointed in the results

Despite the PDP, I am still waiting for solutions
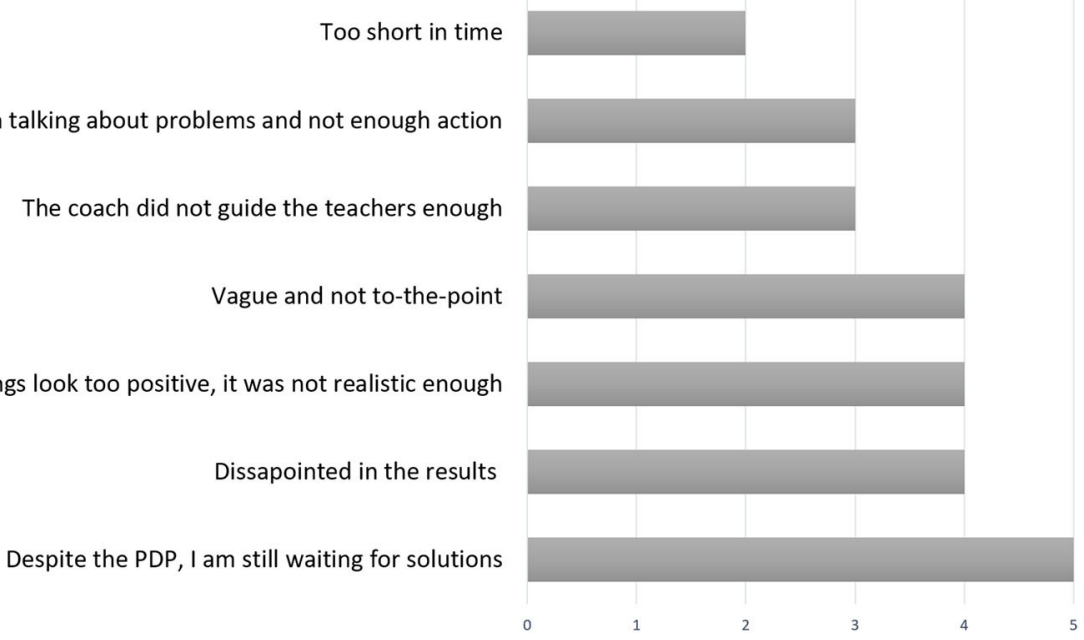

FIGURE 6 | Number of teachers who mentioned this disadvantage of the PDP.

it seem so easy like there were only advantages, while in the classroom it is sometimes a completely different story." Some teachers even pointed out that the PDP reminded them of their teacher education programme where everything seemed much easier until they stepped into the classroom and experienced the so-called practice shock. Finally, a third wave of criticisms directed toward the PDP concerned the coach, who they felt stayed too much in the background and did not guide them enough and the fact that the programme was too superficial and too short (Figure 6).

By comparing these advantages and disadvantages with the content of the PDP and the three phases: (1) goals and reality, (2) help and action and (3) deepening and embedding, several conclusions can be drawn. For instance, the first phase demanded too much of their time. Participating teachers thought it was helpful to discuss their classroom situations with their colleagues, but they felt that they kept talking and discussing rather than looking for solutions, especially during the second phase. During this phase many felt a bit lost, as the intention of the programme was that they learned how to look for solutions themselves. Several teachers experienced this as simply "bumbling around." They expected that the coach would give them more guidance toward solutions or felt that they did not have the energy to do the extra work in their spare time. For example, Chelsey stated: "My colleagues took over my lessons so I could attend a session with some others that took almost three hours where the only thing I did was talking and listening. In the end I needed to search for solutions in the evenings and weekends on my own." However, participating teachers were more enthusiastic about the last phase of the programme. They felt that the PDP had succeeded in making them talk to each other and, during this process, they realized that they must collaborate more. Moreover, most teachers agreed that, to develop solutions in the classrooms, deepening and embedding at the school level is needed. In conclusion, the PDP did not achieve the desired results. Teachers felt there were few changes in their classroom practices after participating in the PDP. Nevertheless, the PDP had set a process in motion and every teacher who was interviewed agreed that they looked forward to working further on this at the school level.

\section{DISCUSSION OF THE RESULTS}

Teachers are expected to create an inclusive classroom where students with different abilities, backgrounds and interests all learn together (Bartolo et al., 2007). Differentiated instruction (DI) is a pedagogical-didactical approach designed to accommodate differences in learning among students (Tomlinson, 2017). However, teachers struggle to implement strategies to create inclusive classrooms (Groenez et al., 2018) and studies on DI have concluded that professional development is needed for teachers to implement differentiated practices successfully (Hootstein, 1998; Brighton et al., 2005). To respond to the demand for inclusive practices from teachers on the one hand, and teachers being unprepared for this on the other, professional development is recommended to help teachers adopt strategies, such as DI and create more inclusive classrooms. This study therefore explored the effectiveness of and satisfaction with a professional development programme (PDP) about inclusive education on teachers' implementation of DI in primary schools. Using a quasi-experimental design, both a survey $(n=284)$ and additional interviews $(n=8)$ were conducted to investigate this issue.

Ideally an increase was found between the two measurements moments in teachers' self-reported philosophy and DI practices. However, in only two factors out of five from the DI-Quest instrument were there a significant difference between the first and the second measurement and neither had increased in a positive direction. The growth mindset of teachers decreased in both the experimental and control group, but no significant 
results were found between the groups. However, the factor output $=$ input changed significantly over time and between the control and experimental group. This factor represents the importance of using ongoing assessment as a tool for both students and teachers in learning and teaching. The results showed that the control group once again exhibited a decrease; however, the results for the experimental group remained steady and the differences between the two groups were significant. Although no statistically significant results were found for adaptive teaching, there is a clear trend toward an increase in both the large quantitative data and in the qualitative sample. Teachers in the interviews also confirmed that they did not implement DI more often after participating in the PDP but did feel more confident in adopting differentiated practices. This is consistent with previous research that found teachers with more training felt more confident in implementing DI (Casey and Gable, 2012). In general, however, the statistical results were not as positive as had been hoped. Some explanations for this lack of improvement are now provided.

The first explanation relates to the treatment fidelity of the intervention. This refers to the fact that many educators struggle to implement interventions and practices consistently (CollierMeek et al., 2013). The PDP was developed by a research team and facilitated by coaches in schools. These coaches participated in a training programme to prepare them for the role. Moreover, they received materials (slide shows, tutorials, video material etc.) and were given the opportunity to tailor these materials to the needs of the school. However, this may have created differences between the intended and implemented PDP. The intention of the PDP was to create a research-oriented attitude among the participants and encourage them to find answers to their learning and practical questions (Bradbury, 2015). The role of teachers as being a researcher who is able to formulate questions and find answers is critical as it encourages them to retain ownership of their professional development. During the interviews, teachers pointed out that they felt too much on their own and failed to find the solutions themselves. Some teachers claimed that not finding answers to their questions was due to a lack of guidance from the coach. Although the coaches in our PDP were trained to coach their core teams at the schools, this training might not have been extensive enough to prepare them for this crucial role. Latz et al. (2008) concluded that, for a successful mentoring programme, time must be given to the process of correspondence, observations and meetings. There may therefore have been insufficient time to prepare some of the coaches for this crucial role or to build a positive relationship. Collecting more in-depth information on this crucial role and the fragile relationship between a coach and teacher would be a definite recommendation for future research. Caution is also needed when drawing conclusions from the qualitative findings as these only represent three out of the eighteen schools participating in the PDP. There is also no current information on how the coaches implemented the PDP in these schools and whether they did this consistently with the materials provided. In addition teachers could choose the goals they wanted to work because literature states that, if the starting point is the needs and questions of teachers themselves, they are the owners of what and how they learn (Merchie et al., 2016). Sometimes these were very broad (e.g., investing more in evaluation) and sometimes these were more specific (e.g., investing in a specific differentiated teaching strategy). Each goal was tailored to creating more inclusive classrooms. But there was a variation between teachers and schools, which made it more difficult to oversee how the PDP was implemented.

A second plausible explanation concerns the fact that the first measurement of the survey took place at the beginning of the academic year and the second at the end. At the beginning teachers were more excited and enthusiastic about starting teaching again after the summer holidays, while they were more exhausted at the end before the summer break. This was also noticeable in the response rate, which decreased from $76 \%$ in the beginning to $46 \%$ at the end. There were no significant differences found in the response rate and teachers' background variables.

A third explanation is that implementing DI requires a great deal of time and effort and that the PDP did not take place for long enough to establish such changes. Although the participants were critical of the PDP, almost all were glad to have been part of it and would like to continue their professional development. Previous research has demonstrated that the biggest challenge for most teachers is that DI questions their prior beliefs about teaching and learning (Brighton et al., 2005). This type of change takes time. Smit and Humpert (2012) also contend that changing teaching habits requires more than 2 years. Initially a third measurement was planned for the next academic year but, due to the drop out of respondents in the second measurement moment and the funding that ended the next year, it was decided to cancel the third survey. However, a recommendation for future research is to create a third measurement moment in the next academic year and to extend the PDP for a second year. This comes with the risk that the response rate will decrease even further if teachers are asked to complete the same questionnaire repeatedly, but this will provide us with more insight into change over time.

A final explanation can be linked to the instrument. The DIQuest is designed to measure teachers' perceptions of their own philosophy and practice. Although DI is part of the intervention, the intervention is not specifically oriented toward DI as it is broader in scope. The question that arises is: did the PDP affect teachers self-reported philosophy and DI practices or did the instrument fail to demonstrate the effects? The survey data provides information on self-reported practices, which are a good indicator of actual classroom behavior (Haney et al., 2002). However, self-reports are not as trustworthy as observations of their actual behavior. For example, teachers may overestimate their abilities or lack the skills to accurately assess what they can accomplish (Feldman and Özalp, 2019). It is also plausible that teachers became more self-critical when completing the survey for a second time because they have had to think it through, a point several of them raised during the interviews. Moreover, some of the advantages of the PDP, such as increasing collaboration between colleagues, were not measured by the DI-Quest. In future research classroom observations could also be conducted to give more insight into teachers' classroom behaviors before and after the PDP. 
Fortunately, some positive signals were received from the interviews with teachers who participated in the PDP. Although changes in classroom actions continued to be hampered, teachers started thinking about their actions. They became more aware of the differentiated practices they were already implementing. They might not have had the intention to implement new differentiated practices, but with the differentiated practices they had already adopted, they implement them now with more intention of creating more inclusive classrooms. For example, previously they randomly grouped the students during an assignment and, after participation in the PDP, they consciously think about the composition of subgroups to consider students' differences. Probably the most valuable contribution of the PDP is that it made teachers realize they need to work together more often. They enjoyed exchanging information and came to the realization that their individual problems in the classroom mean more at the school level. This is consistent with previous studies that have found a common vision within the school can enhance the creation of inclusive classrooms (Fullan, 2007; Beecher and Sweeny, 2008; Smit and Humpert, 2012). Specifically, having a school development plan that contains a common school vision and policy in place to facilitate the implementation of DI encourages teachers to work together and implement strategies successfully. The PDP had two main goals: (A) to instill a more positive mindset to appreciate and exploit diversity in the classroom and (B) to establish collaboration between teachers. Our results confirmed that both goals had not yet been achieved, but the PDP had begun to set the process in motion. This is not yet visible in the statistics, but signals from the teachers demonstrate their motivation to work on DI and inclusive education in general. It takes time for good things to happen.

To conclude, one final point needs to be addressed. In PDP studies, the aim is to determine statistical effects to know whether they are effective. To ensure this happens, a PDP should focus on exactly the things it needs to measure, be robust, not very flexible, and be exactly the same in every school. This contradicts literature that states professional development is only successful if teachers are active participants, if they have a voice in what and how they learn things and if the PDP is tailored to the specific context (Merchie et al., 2016). Therefore, it is important to look further than statistical effects in research on professional development. To obtain a more complete picture of the effectiveness of professional development, research methods should be triangulated because the development of teachers' competences cannot simply be assessed on the basis of statistical information. Professional development is a complex process and it is a challenge for researchers to capture this process as a whole.

\section{CONCLUSION}

Recent theories about DI agree that it is both a philosophy of teaching and a practice of teaching (Coubergs et al., 2017; Tomlinson, 2017). DI is then perceived as a pedagogical model, an approach to teaching and not as a set of individual teaching practices. However, this way of perceiving DI also demands professional development for teachers to learn this model of teaching. Brighton et al. (2005) stated that the biggest challenge for most teachers is that DI questions their previous beliefs. This ties in with our emphasis on teachers' philosophy and the importance of considering DI as a pedagogical model. To participate in professional development, teachers need to have/keep an open mind in order to respond to new forms of diversity and new opportunities for collaborating with colleagues. The PDP aimed to accomplish this through inquiry-based learning. This demands an active investigative attitude on the part of teachers that encourages critical reflection on their own classroom practices (Harinck and van Brakel, 2009). However, in our results, the teachers complained about this approach. Some teachers were still under the impression that there are tailormade solutions available for creating inclusive classrooms, while the reality is more complex. Hence, this programme recalls the importance of the role of the coach in such trajectories. Although continued professional development is necessary and important for teachers, it is a complex process. We refer to the work of Merchie et al. (2016) who identified nine characteristics of effective professional development, with one of them being that the supervisor is of high quality and is competent when it comes to giving and receiving constructive feedback and imparting other coaching skills (Merchie et al., 2016). Our results seem to confirm that it is crucial for the coach to find a balance between letting teachers learn and work on specific aspects of teaching of their choosing and to ensure, at the same time, that they are working toward the desired goal of professionalization. The literature states that professional development is only successful if teachers are active participants, if they have a voice in what and how they learn things and if the PDP is tailored to the specific context (Merchie et al., 2016). However, PDP often works toward a specific goal which is not always very flexible. A suitable coach is able to find a balance between these two extremes. Or, specifically within inquiry-based learning, as an example, the coach needs to find the fragile balance between telling the teachers what to do and letting them find their own answers. Finding such a balance and guiding teachers toward looking for and finding the answers they need is important if we wish to establish the desired improvement that we want to see in teachers' professional development. In this regard, Willegems et al. (2016) plead for the role of a broker as a bridge-maker in professional development trajectories, in addition to the role of coach (Willegems et al., 2016).

In addition, our results also confirmed that collaboration is indeed essential for effective professionalization (Merchie et al., 2016) and beneficial for DI implementation (Latz et al., 2008; de Neve et al., 2015). Teachers reported positive experiences in discussing their individual learning activities and became aware of the need to work together on the collective development of knowledge in the school. They all agreed that, to implement DI, they needed to collaborate more. A common school vision and policy is necessary for the implementation of specific differentiated measures, as these currently differ between teachers and grades and can be confusing for students. This is consistent with previous research that states that collaboration is crucial for creating inclusive classrooms (Mortier et al., 2010; EADSNE (European Agency for Development in Special Needs Education), 
2012). A first step in this process is realizing that collaboration is beneficial for both teachers and students [EADSNE (European Agency for Development in Special Needs Education), 2012].

This study agrees with the literature on the importance of continued professional development for teachers, especially with regard to training and supporting them in complex teaching skills such as creating inclusive classrooms. However, the results of the fourth study also highlight that professional development is complex and, although theories about, for example, inquirybased learning are promising, in reality this does not always lead to immediate improvement in teachers' reported philosophy and practice in terms of DI. Professional development requires patience, time and effort, especially professionalization of complex concepts such as DI that do not involve an easy fix, but involve a mind-shift if teachers do not yet believe in the benefits of DI.

\section{DATA AVAILABILITY STATEMENT}

The datasets generated for this study will not be made publicly available. The datasets are part of a large-scale research project.

\section{REFERENCES}

Baert, H., de Witte, K., Govaerts, N., and Sterck, G. (2011). Werk Maken Van Leren. Antwerpen: Garant.

Bartolo, P., Janik, I., Janikova, V., Hofsass, T., Koinzer, P., Vilkiene, V., et al. (2007). Responding to Students' Diversity. Teacher's Handbook/Tutor's Handbook. Malta: University of Malta.

Beecher, M., and Sweeny, S. M. (2008). Closing the achievement gap with curriculum enrichment and differentiation: one school's story. J. Adv. Academica 19, 502-530. doi: 10.4219/jaa-2008-815

Bengtsson, M. (2016). How to plan and perform a qualitative study using content analysis. NursingPlus Open 2, 8-14. doi: 10.1016/j.npls.2016.01.001

Bradbury, H. (2015). The Sage Handbook of Action Research. London: SAGE Publications Ltd. doi: 10.4135/9781473921290

Brighton, C. M., Hertberg, H. L., Moon, T. R., Tomlinson, C. A., and Callahan, C. M. (2005). The Feasibility of High-End Learning in a Diverse Middle School. Connecticut: National Research Center on the Gifted and Talented.

Casey, M. K., and Gable, R. K. (2012). "Perceived efficacy of beginning teachers to differentiate instruction," Paper Presented at the 44th Annual Meeting of the New England Educational Research Association (Portsmouth, NH).

Clement (2015). Inspirerend coachen: de kunst van dynamisch en uitdagend communiceren; voor leidinggevenden, coaches, ouders, leraren en begeleiders. Leuven: Lannoocampus.

Collier-Meek, M. A., Fallon, L. M., Sanetti, L. M., and Maggin, D. M. (2013). Focus on implementation: assessing and promoting treatment fidelity. Teach. Except. Children 45, 52-59. doi: 10.1177/004005991304500506

Corno, L. Y. N. (2008). On teaching adaptively. Educ. Psychol. 43, 161-173. doi: 10.1080/00461520802178466

Coubergs, C., Struyven, K., Vanthournout, G., and Engels, N. (2017). Measuring teachers' perceptions about differentiated instruction: the DI-Quest instrument and model. Stud. Educ. Eval. 53, 41-54. doi: 10.1016/j.stueduc.2017.02.004

de Neve, D., Devos, G., and Tuytens, M. (2015). The importance of job resources and self-efficacy for beginning teachers' professional learning in differentiated instruction. Teach. Teacher Educ. 47, 30-41. doi: 10.1016/j.tate.2014.12.003

Dweck, C. S. (2006). Mindset: The New Psychology of Success. New York, NY: Random House.

EADSNE (European Agency for Development in Special Needs Education) (2012). Lerarenopleiding en Inclusie. Profiel van Inclusieve Leraren. Odense; Brussel: European Agency for Development in Special Needs Education.

\section{ETHICS STATEMENT}

Ethical review and approval was not required for the study on human participants in accordance with the local legislation and institutional requirements. The patients/participants provided their written informed consent to participate in this study.

\section{AUTHOR CONTRIBUTIONS}

All authors contributed to the design and implementation of the research, discussed the results, and contributed to the final manuscript.

\section{FUNDING}

The authors of this study gratefully acknowledge the support of the POTENTIAL research and valorisation project (www. potentialproject.be), funded by the Flanders Innovation and Entrepreneurship (VLAIO).
Edyburn, D. L. (2005). Universal design for learning. Spec. Educ. Technol. Pract. $7,16-22$.

Feldman, A., and Özalp, D. (2019). Science teachers' ability to self-calibrate and the trustworthiness of their self-reporting. J. Sci. Teacher Educ. 30, 280-299. doi: 10.1080/1046560X.2018.1560209

Fullan, M. (2007). The New Meaning of Educational Change. New York, NY: Teacher College Press. Columbia University.

Gijbels, D., Dochy, F., van den Bossche, P., and Segers, M. (2005). Effects of problem-based learning: a meta-analysis from the angle of assessment. Rev. Educ. Res. 75, 27-61. doi: 10.3102/00346543075001027

Groenez, S., Vantieghem, W., Lamberts, M., and van Avermaet, P. (2018). "Diversiteitsbarometer onderwijs vlaamse gemeenschap," in: Diversiteitsbarometer Onderwijs (Brussels: Unia), 47-193.

Haney, J. J., Lumpe, A. T., Czerniak, C. M., and Egan, V. (2002). From beliefs to actions: the beliefs and actions of teachers implementing change. J. Sci. Teacher Educ. 13, 171-187. doi: 10.1023/A:1016565016116

Harinck, F., and van Brakel, D. (2009). Professionalisering Door Praktijkonderzoek: Leraren Onderzoeken Hun Eigen Praktijk. Antwerpen: Garant

Hattie, J. (2009). Visible Learning: A Synthesis of Over 800 Meta-analyses Relating to Achievement. Taylor \& Francis Ltd.

Hootstein, E. (1998). Differentiation of Instructional Methodologies in SubjectBased Curricula at the Secondary Level. Richmond, VA: Metropolitan Educational Research Consortium.

Keay, J. K., and Lloyd, C. M. (2011). "Developing inclusive approaches to learning and teaching," in Linking Children's Learning with Professional Learning. Impact, Evidence and Inclusive Practice, eds J. K. Keay and C. M. Lloyd (Rotterdam: Sense Publishers), 31-44. doi: 10.1007/978-94-6091-645-8_3

Latz, A. O., Speirs Neumeister, K. L., Adams, C. M., and Pierce, R. L. (2008). Peer coaching to improve classroom differentiation: perspectives from project CLUE. Roeper Rev. 31, 27-39.

Lawrence-Brown, D. (2004). Differentiated instruction: inclusive strategies for standards-based learning that benefit the whole class. Am. Sec. Educ. 32, 34-62.

Lindner, K. T., Alnahdi, G. H., Wahl, S., and Schwab, S. (2019). Perceived differentiation and personalization teaching approaches in inclusive classrooms: perspectives of students and teachers. Front. Educ. 4:58. doi: 10.3389/feduc.2019.00058

Merchie, E., Tuytens, M., Devos, G., and Vanderlinde, R. (2016). Evaluating teachers' professional development initiatives: towards an extended evaluative framework. Res. Pap. Educ. 33, 143-168. doi: 10.1080/02671522.2016.1271003 
Mortier, K., Hunt, P., Leroy, M., van de Putte, I., and van Hove, G. (2010). Communities of practice in inclusive education. Educ. Stud. 36, 345-355. doi: 10.1080/03055690903424816

OECD (2010). Educating Teachers for Diversity: Meeting the Challenge. Paris: OECD. doi: 10.1787/9789264079731-en

Smit, R., and Humpert, W. (2012). Differentiated instruction in small schools. Teach. Teacher Educ. 28, 1152-1162. doi: 10.1016/j.tate.2012. 07.003

Sousa, D. A., and Tomlinson, C. A. (2011). Differentiation and the Brain: How Neuroscience Supports the Learner-Friendly Classroom. Solution Tree Press.

Tomlinson, B. (ed.). (2011). Materials Development in Language Teaching. Cambridge University Press.

Tomlinson, C. A. (2014). The Differentiated Classroom: Responding to the Needs of all Learners. Alexandria: ASCD.

Tomlinson, C. A. (2017). How to Differentiate Instruction in Academically Diverse Classrooms. Alexandria: ASCD.

Tomlinson, C. A., Brighton, C., Hertberg, H., Callahan, C. M., Moon, T. R., Brimijoin, K., et al. (2003). Differentiating instruction in response to student readiness, interest and learning profile in academically diverse classrooms: a review of the literature. J. Educ. Gifted 27, 119-145. doi: $10.1177 / 016235320302700203$

Tomlinson, C. A., and Imbeau, M. B. (2010). Leading and Managing a Differentiated Classroom. Alexandria: ASCD.
UNESCO (2016). Learning for All: Guidelines on the Inclusion of Learners with Disabilities in Open and Distance Learning. Paris: UNESCO.

Whitburn, J. (2001). Effective classroom organisation in primary schools: mathematics. Oxford Rev. Educ. 27, 411-428. doi: 10.1080/03054980125200

Willegems, V., Consuegra, E., Struyven, K., and Engels, N. (2016). How to become a broker: the role of teacher educators in developing collaborative teacher research teams. Educ. Res. Eval. 22, 173-193. doi: 10.1080/13803611.2016.1247721

Yuen, C. (2009). Dimensions of diversity: challenges to secondary school teachers with implications for intercultural teacher education. Teach. Teacher Educ. 26, 732-741. doi: 10.1016/j.tate.2009.10.009

Conflict of Interest: The authors declare that the research was conducted in the absence of any commercial or financial relationships that could be construed as a potential conflict of interest.

Copyright $(2020$ Gheyssens, Consuegra, Engels and Struyven. This is an open-access article distributed under the terms of the Creative Commons Attribution License (CC $B Y)$. The use, distribution or reproduction in other forums is permitted, provided the original author(s) and the copyright owner(s) are credited and that the original publication in this journal is cited, in accordance with accepted academic practice. No use, distribution or reproduction is permitted which does not comply with these terms. 